\title{
Genotype by environment interaction for growth and survival rate in black tiger shrimp (Penaeus monodon) in generation 4
}

\author{
Sang V. Nguyen*, Luan T. Nguyen, \& Nhien V. Tran
}

Research Institute for Aquaculture No. 2, Ho Chi Minh City, Vietnam

ARTICLE INFO
Research Paper
Received: May 02, 2019
Revised: August 01, 2019
Accepted: August 08, 2019
Keywords
Black tiger shrimp
Genotype by environment interaction
Growth
Survival rate

\section{${ }^{*}$ Corresponding author}

Nguyen Van Sang Email: nguyenvansang1973@yahoo.com

\begin{abstract}
Genotype by environment interaction for growth rate in G1 of the same selection program has been published. However, there is no repeated figure in later generations for confirming and well-planning the design of selection program for further improvement. The experiment was conducted using selective population of generation 4 with 97 families tested in 3 environments. Growth (body weight) and survival rate at harvest weight were recorded and evaluated. There was no genotype by environment interaction for both traits with high genetic correlations of the same traits tested between ponds in the Central and in the South of Vietnam of 0.80 and 0.83 , respectively. There was also no genotype by environment interaction for growth rate between ponds in the South of Vietnam and bio-security indoor tank with high genetic correlation of 0.91 . These results indicated that the number of testing environments would be reduced to save the operation cost for a breeding program. Estimated genetic response was from moderate to high for growth trait corresponding to moderate to high heritabilities $(0.20-0.45)$ and high for survival rate corresponding to high heritabilities $(0.34$ - 0.45).
\end{abstract}

Cited as: Nguyen, S. V., Nguyen, L. T., \& Tran, N. V. (2019). Genotype by environment interaction for growth and survival rate in black tiger shrimp (Penaeus monodon) in generation 4 . The Journal of Agriculture and Development 18(5), 24-32. 


\title{
Tương tác giữa kiểu gen và môi trường đến tính trạng tăng trưởng và tỷ lệ sống trên tôm sú (Penaeus monodon) chọn giống thế hệ thứ 4
}

\author{
Nguyễn Văn Sáng*, Nguyễn Thành Luân \& Trần Văn Nhiên \\ Viện Nghiên Cứu Nuôi Trồng Thủy Sản II, TP. Hồ Chí Minh
}

\section{THÔNG TIN BÀI BÁO}

Bài báo khoa học

Ngày nhận: 02/05/2019

Ngày chỉnh sửa: $01 / 08 / 2019$

Ngày chấp nhận: 08/08/2019

\section{Từ khóa}

Tăng trưởng

Tôm sú

Tương tác kiểu gen và môi trường

Tỷ lệ sống

*Tác giả liên hệ

Nguyễn Văn Sáng

Email: nguyenvansang1973@yahoo.com

\section{TÓM TẮT}

Tương tác giữa kiểu gen và môi trường tính trạng tăng trưởng đã được công bố trên quần thể chọn giống G1 cùng chương trình, nhưng chưa có dữ liệu lặp lại trên các thế hệ tiếp theo nhằm khẳng định sự tồn tại tương tác này hay không và có định hướng tốt cho thiết kế chương trình chọn giống tiếp theo. Nghiên cứu được thực hiện trên 97 gia đình tôm sú chọn giống thế hệ thứ 4 nuôi ở 3 môi trường khác nhau. Hai tính trạng tăng trưởng (khối lượng) và tỷ lệ sống được đánh giá trên tôm khi thu hoạch. Kết quả phân tích cho thấy không có tương tác kiểu gen và môi trường đối với tính trạng tăng trưởng và tỷ lệ sống, trong đó tương quan di truyền cùng tính trạng ở hai môi trường ao nuôi miền Trung và miền Nam tương ứng là 0,80 và 0,83 . Không có tương tác kiểu gen và môi trường cho tính trạng tăng trưởng giữa tôm nuôi ao ở miền Nam và bể an toàn sinh học trong nhà với tương quan di truyền là 0,91 . Hiệu quả chọn lọc ước tính mang lại ở mức trung bình đến cao cho tính trạng tăng trưởng và cao cho tính trạng tỷ lệ sống với hệ số di truyền tương ứng là $0,20-0,45$ và $0,34-0,45$.

\section{1. Đặt Vấn Đề}

Tôm sú (Penaeus monodon) được nuôi phổ biến ở Việt Nam trong các mô hình nuôi khác nhau. Mô hình nuôi cho sản lượng cao là bán thâm canh và thâm canh, tập trung chính ở miền Trung và miền Nam (MARD, 2015). Hàng năm, nhu cầu tôm sú bố mẹ ước khoảng 30.000 con và nguồn tôm bố mẹ hiện nay chủ yếu được đánh bắt từ tự nhiên, đầm ao nuôi quảng canh và số ít từ chọn giống (DF, 2018). Việc dựa vào nguồn tôm bố mẹ từ tự nhiên và từ đầm nuôi là nguồn lan truyền mầm bệnh cũng như làm giảm nguồn lợi.

Do đó, chương trình chọn giống và sản xuất tôm sú bố mẹ trong diều kiện an toàn sinh học là rất cần thiết. Yêu cầu của chương trình chọn giống phải đảm bảo đánh giá các tính trạng và chọn lọc dựa trên các thông số di truyền tính toán được từ các gia đình tôm nuôi theo các môi trường hay mô hình nuôi phổ biến để đảm bảo tính chính xác cho chọn lọc và mang lại hiệu quả cao. Tuy nhiên, tôm chọn giống phải thực hiện trong điều kiện an toàn sinh học (ATSH) để đảm bảo sạch bệnh, trong khi người dân nuôi tôm thương phẩm trong ao, nên cần có đánh giá tương tác kiểu gen và môi trường.

Tương tác kiểu gen và môi trường $(\mathrm{G} \times \mathrm{E})$ xuất hiện khi một môi trường nuôi nào đó thay đổi làm thay đổi đáng kể kiểu gen nhiều hơn so với các môi trường nuôi khác. Một cách để ước tính $\mathrm{G} \times \mathrm{E}$ là xem một tính trạng được đánh giá ở các môi trường khác nhau như là các tính trạng khác nhau, từ đó ước tính tương quan di truyền giữa chúng và dựa vào đó để xác định có tương tác $\mathrm{G} \times \mathrm{E}$ hay không. Nếu tương quan di truyền $\left(\mathrm{r}_{\mathrm{g}}\right)$ giữa các tính trạng gần bằng 1 , thì xem như không có tương tác $\mathrm{G} \times \mathrm{E}$ (Falconer \& Mackay, 1996). Theo Robertson (1959) đề nghị rằng tương tác $\mathrm{G} \times \mathrm{E}$ được xem là có ý nghĩa khi $\mathrm{r}_{\mathrm{g}}<0,8$. Trong chọn giống thủy sản, đa số các công bố là không hoặc nếu có thì tương đối thấp về tương tác $\mathrm{G} \times \mathrm{E}$ trên tính trạng tăng trưởng. Một số tác giả cũng thảo luận ở mức $\mathrm{r}_{\mathrm{g}}$ khác nhau và đề xuất 
định hướng của chương trình chọn giống nên như thế nào (Mulder \& Bijma, 2005; Bentsen \& ctv., 2012).

Đối với quần thể tôm sú chọn giống tại Việt Nam, MARD (2018) đã công bố ban đầu về $\mathrm{r}_{\mathrm{g}}$ tính trạng tăng trưởng ở quần thể chọn giống G1. Để có số liệu lặp lại ở các thế hệ chọn giống xa hơn nhằm khẳng định có tồn tại tương tác $\mathrm{G} \times \mathrm{E}$ hay không từ đó định hướng cho chương trình chọn giống hoặc phương pháp chọn lọc, nghiên cứu đánh giá tương tác giữa kiểu gen và môi trường $(\mathrm{G} \times \mathrm{E})$ tính trạng tăng trưởng và tỷ lệ sống đã được thực hiện trên quần thể tôm sú chọn giống thế hệ G4 khi nuôi ở ba môi trường nuôi khác nhau.

\section{Vật Liệu và Phương Pháp Nghiên Cứu}

\subsection{Vật liệu và quần thể chọn giống}

\subsubsection{Ghép cặp cho sinh sản}

Từ 1.067 con tôm thuộc 65 gia đình tôm chọn giống thế hệ thứ 3 (G3) năm 2017 của chương trình chọn giống tại Viện Nghiên cứu Nuôi trồng Thủy sản II từ năm 2013 đến nay. Số tôm này được nuôi tiền thành thục và lựa chọn 784 con (402 cái và 382 đực) thuộc 60 gia đình có khối lượng trên $70 \mathrm{~g} /$ con (tôm đực) và trên $90 \mathrm{~g} / \mathrm{con}$ (tôm cái) có ngoại hình đẹp, túi tinh ở con đực và buồng trứng ở con cái phát triển, tôm sạch các mầm bệnh WSSV, YHV, EHP, IHHNV, LSNV và Vibrio parahaemolyticus, tôm được đeo dấu mắt, dấu đuôi (đối với tôm cái) và bố trí nuôi riêng ở các bể thể tích $10 \mathrm{~m}^{3} /$ bể với số lượng 20 - 30 con/bể. Cho tôm ăn thức ăn tươi sống bao gồm mực, hàu và giun nhiều tơ với tỷ lệ từ $15-20 \%$ khối lượng thân.

Việc tạo ra các gia đình half - sib (cùng cha khác mẹ) và full - sib (cùng cha cùng mẹ) thế hệ $\mathrm{G} 4$ được thực hiện bằng phép phối thứ bậc. Tôm cái thành thục sau khi lột xác, cấy tinh, cắt mắt (Primavera, 1978) và được thả về bể nuôi sinh sản. Hai túi tinh của 1 cá thể tôm đực được cấy cho 2 cá thể tôm cái khác nhau. Căn cứ vào hình dạng và màu sắc của buồng trứng để xác định chính xác giai đoạn phát triển của buồng trứng và chuyển tôm cái vào từng bể đẻ riêng biệt với 1 cá thể tôm cái/bể $1 \mathrm{~m}^{3}$. Thu trứng, rửa trứng, ấp trứng và cuối cùng thu, định lượng, bố trí âu trùng cho giai đoạn ương trong các bể composite theo từng gia đình riêng biệt (MARD, 2018). Tổng số 116 gia đình được sản xuất trong
32 ngày và ấu trùng được ương theo từng gia đình (Bảng 1).

\subsection{2. Ương từ giai đoạn ấu trùng nauplii đến hậu} ấu trùng (PL) và lên kích cỡ đánh dấu

Các gia đình được tiến hành ương trong điều kiện an toàn sinh học. Áp dụng quy trình ương âu trùng tôm sú gia hóa sạch bệnh theo MARD (2018). Mỗi gia đình ương trong 1 bể composite $0,5 \mathrm{~m}^{3}$ (40.000 nauplii/gia đình). Khi tôm đạt $\mathrm{PL}_{4}$ chuyển sang ương bể $1 \mathrm{~m}^{3}$. Khi tôm ở các gia đình đạt cỡ $\mathrm{PL}_{20}$ và nuôi đến kích cỡ đánh dấu trung bình $2,9 \mathrm{~g} / \mathrm{con}$ thì tiến hành 3 lần lọc và giảm mật độ nuôi: $10.000 \mathrm{con} / \mathrm{b} e ̂ ̉, 5.000$ con/bể, $1.000 \mathrm{con} /$ bể và $500 \mathrm{con} / \mathrm{b}$ ể. Sử dụng thức ăn công nghiệp UP (Uni-President), trên $42 \%$ protein, lượng cho ăn dao động từ $10-15 \%$ khối lượng thân tôm/ngày. Chất lượng nước được kiểm soát bằng kết hợp sử dụng vi sinh (Bacillus subtilis, Bacillus licheniformis, Bacillus pumilus tổng mật độ $5 \times 10^{10} \mathrm{cfu} / \mathrm{g}$ ) với liều lượng khác nhau và thay nước tuỳ theo các chỉ tiêu thuỷ hoá gồm $\mathrm{pH}, \mathrm{NH}_{3}, \mathrm{NO}_{2}$ và độ kiềm được đo hằng ngày. Khi đạt kích cỡ đánh dấu, tôm được kiểm tra các bệnh WSSV, YHV, EHP, IHHNV, LSNV và Vibrio parahaemolyticus trước khi đánh dấu. Số lượng gia đình đạt được đến đánh dấu là 97 gia đình, trong đó 76 full-sib và 21 half-sib (Bảng 1).

\section{2. Đánh dấu, nuôi đánh giá tăng trưởng và tỷ lệ sống ở các môi trường nuôi khác nhau}

\subsection{1. Đánh dấu theo gia đình}

Tôm của từng gia đình được chọn ngẫu nhiên để đánh dấu phẩm màu huỳnh quang (Visible Implant Elastomer - VIE) phục vụ nuôi đánh giá các tính trạng với số lượng tương ứng là 45,45 và $60-150 \mathrm{con} /$ gia đình cho 3 môi trường nuôi khác nhau là ao ở Phú Yên (miền Trung), ao ở Bạc Liêu (miền Nam) và bể tuần hoàn an toàn sinh học trong nhà (trong nhà ATSH). Đối với nuôi ATSH trong nhà, một số gia đình không đủ số lượng 150 con thì đánh dấu hết số lượng cá thể còn lại. Năm phẩm màu được sử dụng là đỏ, cam, xanh lá cây, xanh nước biển và trắng, 2 trong 4 vị trí được lựa chọn để đánh dấu ở phần mặt bụng, 2 vị trí ở đốt bụng thứ 1 (bên trái, bên phải) và đốt bụng thứ 6 (bên trái, bên phải). Tổng cộng có $4.365 ; 4.365$ và 9.720 con tôm được đánh dấu cho nuôi tương ứng trong ao $2.000 \mathrm{~m}^{2}$ ở miền Trung, 
Bảng 1. Kết quả sinh sản, ương và đánh dấu, nuôi đánh giá các tính trạng trên quần thể chọn giống G4

\begin{tabular}{lc}
\hline Chỉ tiêu & Kết quả \\
\hline Thời gian sản xuất gia đình & $24 / 03-25 / 04 / 2018$ \\
Khối lượng tôm tham gia sinh sản & $80-90 \mathrm{~g} /$ đực \\
Số lượng gia đình ương thành công đến đánh dấu & $90-110 /$ cái \\
Thời gian từ khi sinh sản đến đánh dấu (ngày, TB \pm SD*) & 97 \\
& $66-108$ \\
Thời gian từ khi đánh dấu đến thu thập số liệu (ngày, TB \pm SD*) & $(75,9 \pm 18,2)$ \\
Số lượng cá thể đánh dấu theo từng gia đình (con/gia đình) theo môii trường & $56-95$ \\
nuôi: & $(90,0 \pm 8,9)$ \\
Ao miền Trung & \\
Ao miền Nam & 45 \\
Trong nhà ATSH & 45 \\
Tổng số cá thể được đánh dầu cho nuôi đánh giá tính trạng theo môi trường & $60-150$ \\
nuôi (con/môi trường): & \\
Ao miền Trung & 4.365 \\
Ao miền Nam & 4.365 \\
Trong nhà ATSH & 9.720 \\
Số lượng cá thể và gia đình thu hoạch theo môi trường nuôi (con và gia & \\
đình): & \\
Ao miền Trung & $2.038,94$ \\
Ao miền Nam & $1.897,96$ \\
Trong nhà ATSH & $8.303,96$ \\
\hline
\end{tabular}

*TB là Trung bình và SD là độ lệch chuẩn.

ao $1.500 \mathrm{~m}^{2}$ ở miền Nam có độ sâu $1,2 \mathrm{~m}$ và 520 $\mathrm{m}^{2}$ bể $\left(2\right.$ bể $60 \mathrm{~m}^{2} /$ bể và 2 bể $200 \mathrm{~m}^{2} /$ bể $)$ trong nhà ATSH có độ sâu 1,0 m. Ao nuôi ở miền Trung tại xã An Hiệp, huyện Tuy An, tỉnh Phú Yên. Ao nuôi ở miền Nam tại Trại Thực nghiệm Thuỷ sản Bạc Liêu, phường Nhà Mát, TP. Bạc Liêu, tỉnh Bạc Liêu. Bể nuôi trong nhà ATSH thuộc Trung tâm Quốc gia Giống Hải sản Nam Bộ, phường Thắng Tam, TP. Vũng Tàu, tỉnh Bà Rịa - Vũng Tàu.

\subsection{2. Đánh giá các tính trạng của các gia đình thế hệ G4}

Kỹ thuật nuôi trong ao tại miền Trung và miền Nam được thống nhất giống nhau, ngoại trừ một số phần khác nhau gồm mật độ $10,5 \mathrm{con} / \mathrm{m}^{2} \mathrm{so}$ với $13,3 \mathrm{con} / \mathrm{m}^{2}$ và thời gian nuôi trung bình là 56 ngày so với 64 ngày. Ngoài số lượng tôm đánh dấu như đã nêu ở trên, tôm không đánh dấu tương ứng 16.350 con và 15.350 con cũng được thả nuôi chung để đạt mật độ này.

Kỹ thuật nuôi trong bể ATSH trong nhà được thực hiện như mô tả của MARD (2018) với mật độ dao động 16 - 20 con $/ \mathrm{m}^{2}$ tuỳ theo bể nuôi, thức ăn viên Lucky star (Taiwan Hung Kuo Industrial Co., Ltd.), kiểm soát chất lượng nước như mô tả trong phần ương ở bên trên và thời gian nuôi là 70 - 95 ngày tuỳ theo bể nuôi (Bảng 1).

\subsection{Thu thập và xử lý số liệu}

\subsubsection{Thu thập số liệu}

Sau thời gian nuôi đánh giá các tính trạng, các số liệu thu thập gồm tổ hợp dấu, giới tính, khối lượng cho từng cá thể và tỷ lệ sống theo từng gia đình. Tổng số tôm còn sống và truy được dấu cho thu thập số liệu theo từng môi trường nuôi tương ứng là $2.038 ; 1.897$ và 8.303 con, với số lượng cá thể dao động $3-42$ con, $4-39$ con và $16-149$ con thuộc tương ứng 94,96 và 96 gia đình cho ao nuôi miền Trung, miền Nam và bể trong nhà ATSH.

\subsubsection{Xử lý số liệu}

Số liệu được quản lý và kiểm tra bằng phần mềm Microsoft Excel 2016. Các phương sai thành 
phần và thông số di truyền được ước tính bằng phần mềm ASReml phiên bản 3.0 (Gilmour \& ctv., 2009). Dữ liệu phả hệ cho xử lý số liệu được truy xuất đến quần thể chọn giống ban đầu $\mathrm{G}_{0}$.

Đối với tính trạng tăng trưởng (khối lượng lúc thu hoạch), mô hình tuyến tính hỗn hợp cá thể được sử dụng. Ảnh hưởng cố định thử nghiệm đưa vào mô hình toán bao gồm khối lượng tôm mẹ, khối lượng tôm bố, ngày sinh sản, thời gian ương đến đánh dấu, khối lượng lúc đánh dấu (TW), thời gian nuôi tăng trưởng từ lúc đánh dấu đến cân đo (GrowAge), thời gian nuôi tăng trưởng từ PLs đến cân đo, giới tính (Sex), nhưng sau đó loại những ảnh hưởng không có ý nghĩa thống kê còn giữ lại $\mathrm{TW}$, GrowAge và Sex trong mô hình:

$$
\begin{aligned}
\text { Khối lượng }_{\mathrm{ijk}} & =\mu+\operatorname{Sex}_{\mathrm{j}}+\beta_{1} \times \mathrm{TW}_{\mathrm{ijk}} \\
& +\beta_{2} \times \text { GrowAge }_{\mathrm{ijk}}+\text { cá thể } \\
& + \text { tôm mẹk } \\
\mathrm{i} & +\mathrm{e}_{\mathrm{ijk}}
\end{aligned}
$$

Trong đó: Khối lượng iijk là khối lượng của cá thể i khi thu hoạch, $\mu$ là trung bình của quần thể, $\beta_{1}$ là hệ số hồi quy của hiệp biến $\mathrm{TW}_{\mathrm{ijk}}, \beta_{2}$ là hệ số hồi quy của hiệp biến GrowAge $\mathrm{ijk}_{\mathrm{jk}}$, cá thể là ảnh hưởng ngẫu nhiên của cá thể i, cá mẹk là ảnh hưởng ngẫu nhiên của môi trường ương nuôi riêng rẽ đến đánh dấu trùng với ảnh hưởng ngẫu nhiên tôm mẹ và eijk là ảnh hưởng ngẫu nhiên của số dư. Phương sai thành phần ước tính được tương ứng với các ảnh hưởng ngẫu nhiên này gồm $\sigma_{\mathrm{a}}^{2}$ là phương sai di truyền cộng gộp, $\sigma_{\mathrm{c}}^{2}$ là phương sai ảnh hưởng của môi trường ương riêng rẽ, $\sigma_{\mathrm{e}}^{2}$ là phương sai số dư. Phương sai kiểu hình $\sigma_{\mathrm{p}}^{2}=$ $\sigma_{\mathrm{a}}^{2}+\sigma_{\mathrm{c}}^{2}+\sigma_{\mathrm{e}}^{2}$. Hệ số di truyền được ước tính là $\mathrm{h}^{2}=\frac{\sigma_{\mathrm{a}}^{2}}{\sigma_{\mathrm{a}}^{2}+\sigma_{\mathrm{c}}^{2}+\sigma_{\mathrm{e}}^{2}}$ và ảnh hưởng của môi trường ương riêng rẽ được ước tính là c $\mathrm{c}^{2}=\frac{\sigma_{\mathrm{c}}^{2}}{\sigma_{\mathrm{a}}^{2}+\sigma_{\mathrm{c}}^{2}+\sigma_{\mathrm{e}}^{2}}$.

Đối với tính trạng tỷ lệ sống, số liệu dạng nhị phân được sử dụng. Các cá thể còn sống tại thời điểm cân đo thu thập số liệu được mã hóa là 1 , các cá thể không hiện diện tại thời điểm thu hoạch được xem là đã chết và được mã hóa là 0 . Các ảnh hưởng cố định được thử nghiệm đưa vào mô hình toán như mô hình 1 , nhưng chỉ có SPdate và GrowAge ảnh hưởng có ý nghĩa thống kê nên giữ lại trong mô hình. Các phương sai thành phần của tính trạng tỷ lệ sống được ước tính bằng mô hình tuyến tính hỗn hợp cá thể:

$$
\begin{aligned}
& \text { Tỷ lệ sống } \mathrm{ijk}_{\mathrm{j}}=\mu+\text { SPdate }_{\mathrm{j}}+\beta_{1} \\
& \times \text { GrowAge }_{\mathrm{ijk}}+\text { cá thể } \\
& + \text { tôm } \mathrm{mẹ}_{\mathrm{k}}+\mathrm{e}_{\mathrm{ijk}}
\end{aligned}
$$

Trong đó: Tỷ lệ sống ijk là ước tính tuyến tính của tỷ lệ sống cá thể, các ảnh hưởng ngẫu nhiên còn lại như mô tả trong mô hình 1 . Hệ số di truyền và ảnh hưởng của môi trường ương riêng rẽ được ước tính như cho tính trạng tăng trưởng.

Các phương sai thành phần và tương quan di truyền của tính trạng khối lượng thu hoạch và tỷ lệ sống cá thể trong từng môi trường được ước tính bằng các mô hình 2 biến với các ảnh hưởng như mô tả trong Mô hình 1 (cho khối lượng thu hoạch) và mô hình 2 (cho tỷ lệ sống). Vì mỗi cá thể tôm chỉ được nuôi trong một môi trường duy nhất, nên hiệp phương sai của số dư giữa 2 môi trường được đặt là zero. Tương quan di truyền $\left(\mathrm{r}_{\mathrm{a}}\right)$ giữa tính trạng khối lượng thu hoạch và tỷ lệ sống cá thể được ước tính theo công thức $\mathrm{r}_{\mathrm{a}}=\frac{\sigma_{12}}{\sqrt{\sigma_{1}^{2}} \times \sqrt{\sigma_{2}^{2}}}$, trong đó $\sigma_{12}$ là hiệp phương sai của ảnh hưởng di truyền cộng gộp của hai tính trạng, $\sigma_{1}^{2}$ và $\sigma_{2}^{2}$ lần lượt là phương sai của ảnh hưởng di truyền cộng gộp của khối lượng thu hoạch và tỷ lệ sống (Falconer \& Mackay, 1996).

Tương tác giữa kiểu gen và môi trường cho từng tính trạng khối lượng lúc thu hoạch và tỷ lệ sống ở 3 môi trường nuôi (ao miền Trung, ao miền Nam và bể trong nhà $\mathrm{ATSH}$ ) được ước tính thông qua tương quan di truyền $\left(\mathrm{r}_{\mathrm{a}}\right)$ theo mô hình từng cặp 2 biến giống mô hình 1 và mô hình 2 tương ứng cho 2 tính trạng do mô hình ba biến gặp phải vấn đề hội tụ (converged) trong xử lý. $r_{a}$ tính theo công thức $\mathrm{r}_{\mathrm{a}}=\frac{\sigma_{12}}{\sqrt{\sigma_{1}^{2}} \times \sqrt{\sigma_{2}^{2}}}$, trong đó $\sigma_{12}$ là hiệp phương sai của ảnh hưởng di truyền cộng gộp của cùng tính trạng cho 2 môi trường, $\sigma_{1}^{2}$ và $\sigma_{2}^{2}$ lần lượt là phương sai của ảnh hưởng di truyền cộng gộp của cùng tính trạng (khối lượng thu hoạch hoặc tỷ lệ sống) cho 2 môi trường (Falconer \& Mackay, 1996).

\section{Kết Quả và Thảo Luận}

\subsection{Thống kê mô tả các tính trạng}

Trung bình, độ lệch chuẩn (SD, đơn vị tính trạng) và hệ số biến thiên $(\mathrm{CV}, \%)$ các tính trạng $\mathrm{TW}$ và $\mathrm{HW}$ từng cá thể và $\mathrm{SUR}$ theo gia đình 
Bảng 2. Kết quả nuôi đánh giá các tính trạng trên quần thể tôm sú chọn giống G4

\begin{tabular}{|c|c|c|}
\hline \multicolumn{2}{|c|}{ Chỉ tiêu thống kê mô tả theo tính trạng và môi trường nuôi } & Kết quả \\
\hline \multirow{3}{*}{ TW $(g)$} & Trung bình (g) & 2,90 \\
\hline & $\mathrm{SD}(\mathrm{g})$ & 0,60 \\
\hline & $\mathrm{CV}(\%)$ & 20,69 \\
\hline \multicolumn{3}{|l|}{ HW (g) } \\
\hline \multirow{3}{*}{ Miền Trung } & Trung bình (g) & 23,46 \\
\hline & $\mathrm{SD}(\mathrm{g})$ & 8,60 \\
\hline & $\mathrm{CV}(\%)$ & 36,68 \\
\hline \multirow{3}{*}{ Miền Nam } & Trung bình (g) & 22,62 \\
\hline & $\mathrm{SD}(\mathrm{g})$ & 6,36 \\
\hline & $\mathrm{CV}(\%)$ & 28,13 \\
\hline \multirow{3}{*}{ Trong nhà ATSH } & Trung bình (g) & 27,83 \\
\hline & $\mathrm{SD}(\mathrm{g})$ & 9,73 \\
\hline & $\mathrm{CV}(\%)$ & 34,98 \\
\hline \multicolumn{3}{|l|}{ SUR (\%) } \\
\hline \multirow{3}{*}{ Miền Trung } & Trung bình (\%) & 56,79 \\
\hline & $\mathrm{SD}(\%)$ & 19,23 \\
\hline & $\mathrm{CV}(\%)$ & 33,86 \\
\hline \multirow{3}{*}{ Miền Nam } & Trung bình (\%) & 49,45 \\
\hline & SD $(\%)$ & 15,80 \\
\hline & $\mathrm{CV}(\%)$ & 31,95 \\
\hline \multirow{3}{*}{ Trong nhà ATSH } & Trung bình (\%) & 85,90 \\
\hline & $\mathrm{SD}(\%)$ & 17,70 \\
\hline & $\mathrm{CV}(\%)$ & 20,70 \\
\hline
\end{tabular}

TW = khối lượng đánh dấu, $\mathrm{HW}=$ khối lượng thu hoạch, $\mathrm{SUR}=$ tỷ lệ sống, $\mathrm{SD}=$ độ lệch chuẩn, $\mathrm{CV}=$ hệ số biến thiên, ATSH: An toàn sinh học.

ở 3 môi trường nuôi khác nhau được thể hiện trong Bảng 2. HW của tôm nằm trong khoảng kích cỡ tôm thu hoạch phổ biến ở các mô hình nuôi hiện nay, tương ứng là $23,46,22,62$ và 27,83 $\mathrm{g}$ cho các môi trường nuôi miền Trung, miền Nam và trong nhà $\mathrm{ATSH}$. Đối với SUR tương ứng là $56,79,49,45$ và $85,90 \%$ cho 3 môi trường nuôi, cao nhất ở bể nuôi trong nhà ATSH. CV của cả 2 tính trạng HW và SUR tương ứng trong khoảng 28,13 - $36,68 \%$ và $20,70-33,86 \%$ cho 3 môi trường nuôi khác nhau, nằm trong khoảng phổ biến của các tính trạng này trên các đối tượng thuỷ sản khác trên thế giới (Gjedrem, 2005).

\subsection{Hệ số di truyền và tương quan di truyền 2 tính trạng HW và SUR}

Phương sai thành phần $\left(\sigma^{2}\right)$, hệ số di truyền $\left(\mathrm{h}^{2}\right)$, ảnh hưởng của ương riêng rẽ các gia đình đến đánh dấu $\left(c^{2}\right)$ và tương quan di truyền $\left(\mathrm{r}_{\mathrm{a}}\right)$ các tính trạng $\mathrm{HW}$ và SUR trên quần thể tôm G4 nuôi ở các môi trường khác nhau được thể hiện trong Bảng 3 . Hầu hết kết quả $h^{2}, \mathrm{c}^{2}$ và ra khác không (zero) có ý nghĩa thống kê, ngoại trừ $c^{2}$ cho HW ở miền Trung, $c^{2}$ cho SUR trong nhà ATSH và ra giữa $\mathrm{HW}$ và SUR ở miền Trung và trong nhà ATSH. Hệ số di truyền cho tính trạng tăng trưởng (khối lượng thu hoạch, HW) trong khoảng trung bình (tương ứng 0,20 và 0,28 ) ở môi trường ao nuôi miền Trung và miền Nam và ở mức cao $(0,45)$ ở bể nuôi trong nhà ATSH. Với $\mathrm{h}^{2}$ này cho phép chúng ta dự đoán hiệu quả sẽ đạt từ trung bình đến cao nếu chúng ta áp dụng chọn lọc theo HW. Hệ số di truyền cho tính trạng HW trên thế hệ G4 có thấp hơn kết quả nghiên cứu trên quần thể $\mathrm{G} 1$ cùng chương trình chọn giống khi nuôi ở ao $(0,60)$ và ở trong nhà $\operatorname{ATSH}(0,56)$ (Nguyen \& ctv., 2017). Hệ số di truyền của HW trên thế hệ $\mathrm{G} 4$ tương đồng với kết quả được báo cáo của các nghiên cứu trước đây là từ $0,23-0,56$ với thời gian nuôi từ $4-10$ tháng tuổi trên tôm sú (Kenway \& ctv., 2006; Coman \& ctv., 2010; Krishna \& ctv., 2011).

Đối với tính trạng tỷ lệ sống, hệ số di truyền cao được ước tính trong cả 3 môi trường miền Trung, miền Nam và trong nhà ATSH tương ứng là 0,45 , 
0,44 và 0,34 (Bảng 3 ), cho phép chúng ta dự đoán hiệu quả mang lại sẽ cao nếu chúng ta chọn lọc theo tính trạng này. Mặc dù tỷ lệ sống ở bể trong nhà ATSH cao $(85,90 \%)$, nhưng hệ số di truyền thấp hơn ở 2 môi trường còn lại có thể là do hệ số biến thiên $\mathrm{CV}$ của tỷ lệ sống ở môi trường này thấp $(20,70 \%$ so với $31,95 \%$ và $33,86 \%)$. Kết quả $\mathrm{h}^{2}$ ở thế hệ chọn giống $\mathrm{G} 4$ cao hơn kết quả ước tính ở thế hệ G1 cùng chương trình chọn giống (tương ứng là 0,18 và 0,19 cho môi trường nuôi miền Trung và trong nhà ATSH) (MARD, 2018). Kết quả trong nghiên cứu này là tương đồng với khoảng $h^{2}$ được báo cáo bởi Kenway \& ctv. (2006) trong khoảng 0,37 - 0,70 cho tính trạng tỷ lệ sống trên tôm sú được ghi nhận trong các khoảng thời gian nuôi khác nhau từ $4-35$ tuần tuổi.

Tương quan di truyền thuận và khác không (zero) có ý nghĩa thống kê giữa tính trạng tăng trưởng và tỷ lệ sống là 0,46 ở quần thể G4 ở môi trường nuôi miền Nam (Bảng 3), nghĩa là SUR có thể được cải thiện nếu chọn lọc nâng cao HW. Kết quả tương tự được tìm thấy ở quần thể G1 cùng chương trình chọn giống ở môi trường nuôi miền Trung và trong nhà ATSH tương ứng là 0,40 và 0,29 (MARD, 2018).

\subsection{Tương tác kiểu gen và môi trường 2 tính trạng HW và SUR ở 3 môi trường nuôi khác nhau}

Đối với tính trạng tăng trưởng thể hiện qua $\mathrm{HW}$, tương quan di truyền $\left(\mathrm{r}_{\mathrm{a}}\right)$ thuận và cao được tìm thấy giữa các môi trường nuôi ở ao miền Trung, ao ở miền Nam và bể trong nhà $\mathrm{ATSH}$ (Bảng 4). $\mathrm{r}_{\mathrm{a}}$ thuận và cao nhất được tìm thấy giữa ao nuôi miền Nam và bể trong nhà $\mathrm{ATSH}$ $(0,91)$, cho thấy tương tác giữa kiểu gen và môi trường $(\mathrm{G} \times \mathrm{E})$ là không đáng kể giữa 2 môi trường nuôi này. $\mathrm{r}_{\mathrm{a}}$ thuận và cao của $\mathrm{HW}$ giữa tôm nuôi ở ao miền Trung và ao ở miền Nam là 0,80 trong nghiên cứu này cho thấy tương tác $\mathrm{G} \times \mathrm{E}$ không có ý nghĩa lớn về mặt sinh học như nhận xét của Robertson (1959) $\left(\mathrm{r}_{\mathrm{a}} \geq 0,8\right)$. Hai mức $\mathrm{r}_{\mathrm{a}}$ thuận và cao này cho $\mathrm{HW}$ cho thấy trong tương lai có thể giảm bớt chi phí nghiên cứu đánh giá tăng trưởng ngoài thực địa bởi vì kết quả đánh giá tốc độ tăng trưởng ở môi trường nuôi trong nhà ATSH có thể đại diện cho ao nuôi ở miền Nam và cho ao nuôi miền Nam có thể đại diện cho ao nuôi ở miền Trung. Tuy nhiên, trong nghiên cứu này cho thấy có tương tác $\mathrm{G} \times \mathrm{E}$ ở mức thấp do tương quan di truyền thuận của HW giữa tôm nuôi ở ao miền Trung và trong bể ATSH trong nhà $(0,74)$.

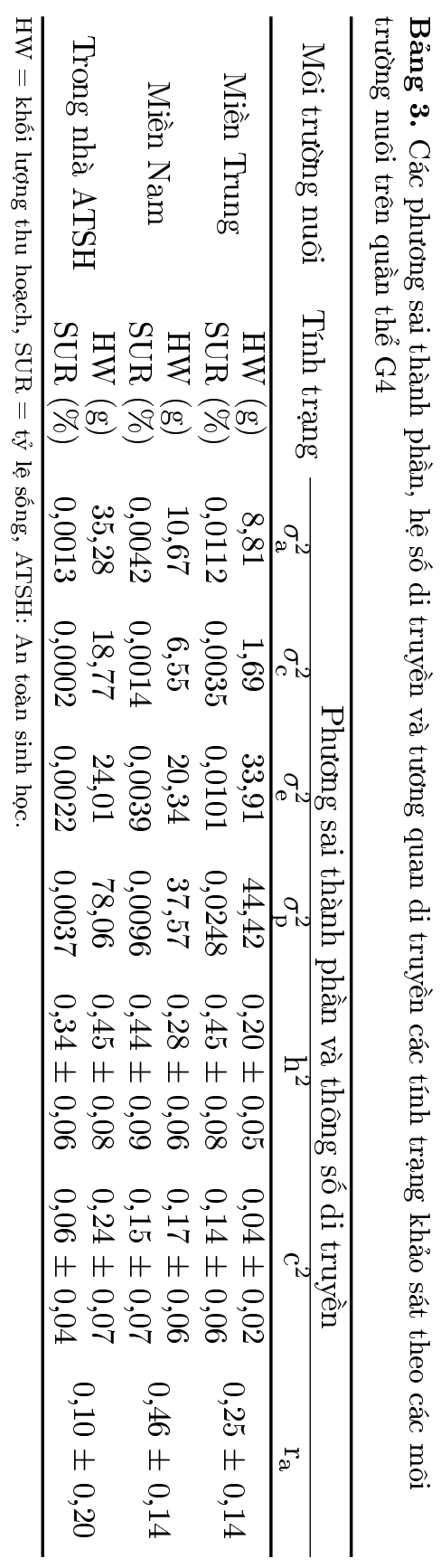


Bảng 4. Tương quan di truyền $\left(\mathrm{r}_{\mathrm{a}}\right)$ cùng tính trạng ở 3 môi trường nuôi khác nhau $\left(\mathrm{r}_{\mathrm{a}}\right)$ (ước tính \pm sai số chuẩn) xem như là 3 tính trạng khác nhau (tương tác kiểu gen và môi trường $-\mathrm{G} \times \mathrm{E}$ ) ở quần thể G4

\begin{tabular}{lcc}
\hline Địa điểm nuôi / Tính trạng & Miền Nam & Trong nhà ATSH \\
\hline HW (g) & $0,80 \pm 0,08$ & $0,74 \pm 0,08$ \\
Miền Trung & & $0,91 \pm 0,03$ \\
Miền Nam & \\
SUR $(\%)$ & $0,83 \pm 0,04$ & $0,02 \pm 0,14$ \\
Miền Trung & & $0,08 \pm 0,13$ \\
Miền Nam & & \\
\hline HW = khối lượng thu hoạch, SUR = tỷ lệ sông, ATSH: An toàn sinh học.
\end{tabular}

Trong tương lai, nếu diện tích nuôi tôm tập trung chính ở miền Nam hơn là miền Trung như hiện nay, thì việc đánh giá $\mathrm{G} \times \mathrm{E}$ ở ao nuôi miền Trung có thể làm tăng thêm chi phí của chương trình chọn giống.

Có tương tác GxE ở mức thấp của $\mathrm{HW}$ giữa ao nuôi miền Trung và bể trong nhà $\operatorname{ATSH}\left(\mathrm{r}_{\mathrm{a}}\right.$ $=0,74)$ ở thế hệ $\mathrm{G} 4$, cũng phù hợp với kết quả thế hệ $\mathrm{G} 1\left(\mathrm{r}_{\mathrm{a}}=0,75\right)$ của cùng chương trình chọn giống cho 2 môi trường nuôi này công bố bởi MARD (2018). Tuy nhiên, không có tương tác $\mathrm{GxE}$ của $\mathrm{HW}$ giữa ao nuôi miền Nam và bể trong nhà $\operatorname{ATSH}\left(\mathrm{r}_{\mathrm{a}}=0,91\right)$ được tính toán ở thế hệ G4, nhưng không có số liệu ở G1. Do đó, để xác định đầy đủ tương tác giữa kiểu gen và môi trường $(\mathrm{G} \times \mathrm{E})$ cho 2 môi trường nuôi này, chúng ta cần xem xét số liệu qua các thế hệ khác . Trong chọn giống thủy sản, một số tác giả cũng đã công bố hầu như không có tương tác $\mathrm{G} \times \mathrm{E}$ hoặc nếu có thì tương đối thấp trên tính trạng tăng trưởng là chính và một vài tính trạng khác trên các đối tượng khác nhau (Gitterle \& ctv., 2005; Gjedrem, 2005; Krishna \& ctv., 2011).

Tương quan di truyền cao $\left(\mathrm{r}_{\mathrm{a}}=0,83\right)$ cho tính trạng tỷ lệ sống được ghi nhận giữa 2 môi trường ao nuôi miền Nam và miền Trung cho thấy việc đánh giá các thông số di truyền cho tính trạng tỷ lệ sống có thể chỉ cần thiết thực hiện tại một trong hai môi trường này để giảm bớt chi phí trong quá trình nghiên cứu. Hệ số tương quan thấp (gần bằng 0 ), lần lượt là $0,08 \pm 0,13$ và 0,02 $\pm 0,14$, khác 0 (zero) không có ý nghĩa thống kê được quan sát giữa hai môi trường nuôi ngoài ao miền Nam và miền Trung với bể nuôi trong nhà ATSH. Các kết quả này chỉ ra rằng, các số liệu ước tính cho tỷ lệ sống trong nhà ATSH không thể sử dụng để đánh giá cho tỷ lệ sống tại môi trường ao nuôi miền Nam và miền Trung.
Trong nghiên cứu này, nếu chúng ta thực hiện chọn giống 2 tính trạng HW và SUR đồng thời thì chúng ta cần thiết phải nuôi đánh giá 2 tính trạng này ở điều kiện nuôi ao miền Nam - là nơi nuôi chính đối tượng tôm sú và dựa vào số liệu nuôi miền Nam để chọn lọc. Khi đó, hiệu quả mang lại sẽ cao cho $\mathrm{HW}$ và SUR cho môi trường nuôi ao miền Nam và tương đối chấp nhận được cho ao nuôi miền Trung $\left(\mathrm{r}_{\mathrm{a}}\right.$ cho $\mathrm{HW}$ giữa ao nuôi miền Nam và miền Trung 0,80 và $\mathrm{r}_{\mathrm{a}}$ cho $\mathrm{SUR}$ là $0,83)$.

\section{Kết Luận}

Ở quần thể tôm sú chọn giống thứ 4 , tương tác kiểu gen và môi trường không đáng kể cho tính trạng tăng trưởng (khối lượng lúc thu hoạch) và tỷ lệ sống với tương quan di truyền cùng tính trạng ở hai môi trường nuôi miền Trung và miền Nam cao. Tương tác kiểu gen và môi trường không đáng kể cho tính trạng tăng trưởng giữa tôm nuôi ao ở miền Nam và bể trong nhà ATSH. Những kết quả này cần được xem xét để áp dụng giảm chi phí nuôi đánh giá ở một hoặc hai môi trường nuôi trong chương trình chọn giống.

Hiệu quả chọn lọc ước tính mang lại ở mức trung bình đến cao cho tính trạng tăng trưởng và cao cho tính trạng tỷ lệ sống do hệ số di truyền tương ứng được tìm thấy trong nghiên cứu.

\section{Lời Cảm Ơn}

Nhóm tác giả xin chân thành cảm ơn Chương trình Ứng dụng Công nghệ Sinh học trong lĩnh vực Nông nghiệp - Thủy sản, Bộ Nông nghiệp và Phát triển Nông thôn cấp kinh phí cho nghiên cứu. Chúng tôi xin trân trọng cảm ơn ThS. Nguyễn Hữu Thanh, ThS. Nguyễn Quyết Tâm 
và TS. La Xuân Thảo đã có đóng góp vào nuôi vỗ, cho sinh sản và ương nuôi quần thể chọn giống thế hệ thứ 4 của nghiên cứu này.

\section{Tài Liệu Tham Khảo (References)}

Bentsen, H. B., Gjerde, B., Nguyen, N. H., Rye, M., Ponzoni, R. W., de Vera, M. S. P., Bolivar, H. L., Velasco, R. R., Danting, J. C., \& Dionisio, E. E. (2012). Genetic improvement of farmed tilapias: Genetic parameters for body weight at harvest in Nile tilapia (Oreochromis niloticus) during five generations of testing in multiple environments. Aquaculture (338), 56-65.

MARD (Ministry of Agriculture and Rural Development). Decision No. 5528/QD-BNN-TCTS dated on December 31, 2015. Planning on culturating brackish water shrimp in Mekong Delta to 2020, with a vision to 2030. Retrieved January 19, 2019 from https://thuvienphapluat.vn/van-ban/linh-vuckhac/quyet-dinh-5528-qd-bnn-tcts-2015-quy-hoachnuoi-tom-nuoc-lo-vung-dong-bang-song-cuu-long365023.aspx.

Coman, G. J., Arnold, S. J., Wood, A. T., \& Kube, P. D. (2010). Age: age genetic correlations for weight of Penaeus monodon reared in broodstock tank systems. Aquaculture (307), 1-5.

Falconer, D. S., \& Mackay, T. F. C. (1996). Introduction to quantitative genetics. Harlow, England: Prentice Hall.

Gilmour, A. R., Gogel, B. J., Cullis, B. R., \& Thompson, R. (2009). ASReml user guide. Hemel Hempstead, UK: VSN International.

Gitterle, T., Rye, M., Salte, R., Cock, J., Johansen, H., Lozano, C., \& Gjerde, B. (2005). Genetic (co) variation in harvest body weight and survival in Penaeus (Litopenaeus) vannamei under standard commercial conditions. Aquaculture 243(1-4), 83-92.

Gjedrem, T. (2005). Selection and breeding programs in aquaculture. (AKVAFORSK) Berlin Germany: Springer.
Kenway, M., Macbeth, M., Salmon, M., McPhee, C., Benzie, J., Wilson, K., \& Knibb, W. (2006). Heritability and genetic correlations of growth and survival in black tiger prawn Penaeus monodon reared in tanks. Aquaculture (259), 138-145.

Krishna, G., Gopikrishna, G., Gopal, C., Jahageerdar, S., Ravichandran, P., Kannappan, S., Pillai, S. M., Paulpandi, S., Kiran, R.P., \& Saraswati, R. (2011). Genetic parameters for growth and survival in Penaeus monodon cultured in India. Aquaculture (318), 74-78.

Mulder, H., \& Bijma, P. (2005). Effects of genotype $\times$ environment interaction on genetic gain in breeding programs. Journal of Animal Science 83, 49-61.

Nguyen, H. H., Nguyen, H. V., Lai, H. V., Phan, Q. M., \& Trinh, T. Q. (2017). Genetic improvement of body weight in black tiger shrimp (Penaeus monodon). Science and Technology Journal of Agriculture and Rural Development (Special issue: plant and livestock breeding), 135-141.

MARD (Ministry of Agriculture and Rural Development). Report No. 633/HD-KHCN-CNSH dated on May, 15, 2018. Application of quantitative genetics and molecular genetics to create the initial material for black tiger shrimp breeding according to growth traits. Retrieved January 19, 2019 from http://sti.vista.gov.vn/tw/Pages/ket-quathnv .aspx?ItemID $=50928$.

Primavera, J. (1978). Induced maturation and spawning in five-month-old Penaeus monodon Fabricius by eyestalk ablation. Aquaculture (13), 355-359.

Robertson, A. (1959). The sampling variance of the genetic correlation coefficient. Biometrics 15, 469-485.

DF (Directorate of Fisheries). 2018. Improving the quality of post larvae from importing stage of broodstock. Retrieved November 12, 2018 from https://tongcucthuysan.gov.vn/vi-vn/nuôi-trồngthủy-sản/-sản-xuất-giống/doc-tin/010001/2018-0306/nang-cao-chat-luong-tom-giong-ngay-tu-khi-nhapkhau-tom-bo-me. 